\title{
Hereditary colon cancer
}

\author{
Dawna M Gilchrist MD FRCPC FCCMG
}

\begin{abstract}
DM Gilchrist. Hereditary colon cancer. Can J Gastroenterol 1997;11(5):421-423. Hereditary colon cancer comprises approximately $10 \%$ of total colon cancer, a disease that affects $6 \%$ of the North American population. Knowledge of molecular genetics of familial adenomatous polyposis and hereditary nonpolyposis colon cancer has improved our diagnostic abilities and management, as well as furthered our understanding of the mechanisms of tumour initiation and progression.
\end{abstract}

Key Words: Familial adenomatous polyposis, Hereditary colon cancer, Hereditary nonpolyposis colon cancer, Tumour

\section{Cancer du côlon héréditaire}

RÉSUMÉ : Le cancer du côlon est de nature héréditaire dans environ $10 \%$ de tous les cas de cancer du côlon, une maladie qui risque d'affecter éventuellement $6 \%$ de toute la population nord-américaine. Les connaissances acquises sur la génétique moléculaire de la polypose adénomateuse familiale et du cancer du côlon héréditaire sans polypes ont contribué à l'amélioration des techniques diagnostiques et thérapeutiques et nous permettent de mieux comprendre les mécanismes de déclenchement et de progression de la tumeur.
$\mathrm{F}$ ully $6 \%$ of the North American population develops colon cancer (1). Approximately $90 \%$ of colon cancer is sporadic; $1 \%$ is due to a hereditary predisposition to familial adenomatosis polyposis (FAP), and $5 \%$ to $10 \%$ to hereditary nonpolyposis colon cancer (HNPCC) (2), previously called Lynch syndrome.

\section{DIAGNOSTIC CRITERIA FOR HEREDITARY COLON CANCER}

- Three or more relatives have histologically proven disease.

- At least two of the affected family members are first-degree relatives.

- At least two generations in a family are affected.

- There is an early age of onset of colon cancer - younger than 40 years old for FAP and younger than 50 years old for HNPCC.
Increased risk in hereditary colon cancer: The relative risk for colon cancer is 2.75 if the proband has two or more affected first-degree relatives. This increases to 5.37 if onset occurs at age younger than 45 years (3).

\section{FAMILIAL ADENOMATOUS POLYPOSIS}

Clinical features: FAP has an incidence of one in 5000 to one in 7500 . Average age of onset of polyps is 25 years, of symptom manifestation is 33 years and of diagnosis is 36 years. Average age of cancer is 42 years. Penetrance, ie, the presence of polyps, is close to $100 \%$ by 40 years.

The name 'familial adenomatosis polyposis' is derived from the presence of hundreds of polyps, with less in the right than in the left colon. Three-quarters of individuals with FAP have inherited the gene from one affected parent; $20 \%$ to $25 \%$ have a new mutation.

Genetics: The gene for FAP, apc, is located on $5 \mathrm{q} 21$. The abnormal gene functions as an autosomal dominant; in its normal state it is a tumour repressor, ie, its natural function is to

Departments of Medicine and Medical Genetics, University of Alberta, Edmonton, Alberta

Correspondence: Dr D Gilchrist, 2E3.28 WC Mackenzie, University of Alberta, Edmonton, Alberta T6G 2R7. Telephone 403-492-7290, fax 403-492-2504, e-mail gilchri@uah.ualberta.ca

Received for publication December 10, 1996. Accepted March 4, 1997 
TABLE 1

Recommendations for monitoring known or suspected familial adenomatosis polyposis/hereditary nonpolyposis colon cancer individuals and their families

\section{Familial adenomatosis polyposis \\ Flexible sigmoidoscopy starting at age 12 years \\ If polyps present, twice yearly testing until surgery \\ If polyps not present, testing every third year until age 40 \\ Upper gastrointestinal testing every one to three years \\ Skull/jaw radiology done once \\ Ophthalmological assessment for CHRPE done once \\ Hereditary nonpolyposis colon cancer \\ Annual colonoscopy starting five years earlier than earliest onset of colon cancer in family \\ For families with extracolonic features: -annual pelvic ultrasound and endometrial biopsy for women -annual clinical examination/endoscopy/diagnostic imaging of organs at risk, as defined by family history}

After colon surgery, biannual endoscopy of remaining colon/rectum

CHRPE Congenital hypertrophy of retinal pigment epithelium

facilitate the removal of unwanted or damaged cells. Most apc alleles have point mutations or small deletions which result in protein truncation. Individuals with FAP have mutations in both the germline and tumour. Somatic mutations to apc are frequently found in sporadic tumours.

Genotype-phenotype correlations: Colonic manifestations may be severe or mild, but most cases are intermediate. Extracolonic manifestations may include adenomatous polyps elsewhere, particularly at the ampulla of Vater or in the gastric mucosa; ocular, cutaneous and skeletal abnormalities in the subset known as Gardner's syndrome (congenital hypertrophy of retinal pigment epithelium [CHRPE] is diagnostic for this condition); and malignancy in other organs, such as mesenteric fibromatosis, thyroid cancer or hepatoblastoma.

\section{HEREDITARY NONPOLYPOSIS COLON CANCER}

Clinical features: The name 'hereditary nonpolyposis colon cancer' is misleading because there may be polyps, but these are much fewer in number than in FAP and are more numerous in the right versus left colon. Mean age of onset is 44 years. In HNPCC type I, only tumours of the colon occur. In HNPCC type II, tumours occur in the colon and elsewhere, especially the endometrium.

Genetics: HNPCC is also an autosomal dominant. Four genes have been implicated. Mutations to hMSH2 at $2 \mathrm{p} 22$ are associated with HNPCC type I; mutations to hMLH1 at 3 p21 are associated with HNPCC type II. Each accounts for approximately $45 \%$ of affected families. Mutations of hPMS1 and hPMS2 are rare.

The normal genes are responsible for DNA mismatch repair. Mutated genes lose this function - it is as if the 'spellcheck' for DNA is off-line.

Mutations to the HNPCC genes are also seen in sporadic tumours.

\section{OTHER HEREDITARY POLYPOID SYNDROMES}

Turcot syndrome: Turcot syndrome involves colonic polyps, colon cancer and primary brain tumours (1). This is likely a recessive condition, and mutations have been shown in apc and HNPCC genes. The former is associated with medulloblastoma; the latter with glioblastoma.

Muir-Torre syndrome: In Muir-Torre syndrome, polyps and colon cancer are associated with skin tumours including basal cell and squamous cell cancer, as well as sebaceous adenoma (4). This is a dominant syndrome and mutations have been demonstrated in MSH2.

Hamartomatous polyposis: Peutz-Jeghers syndrome is a dominant syndrome of mucocutaneous pigmentation and gastrointestinal polyposis with an increased risk of gastrointestinal tumours (1). Juvenile polyposis is also a dominant syndrome, with increased risk of colon tumours. Cowden's disease is yet another dominant syndrome delineated by mucocutaneous growths, breast and thyroid cancer, and gastrointestinal polyps, but with no increased risk of gastrointestinal tumours.

\section{ONCOGENIC THEORY}

The first theory of oncogenesis was proposed by Knudson (5) as a two-hit mechanism best exemplified by retinoblastoma. In this model, the individual inherits a germline mutation in a tumour repressor and then its normal counterpart is independently deactivated.

The multihit model of oncogenesis from Vogelstein et al (6) was first described in FAP. The first hit is a mutation to the apc gene, followed by K-ras oncogene activation and then loss of tumour repressors on $18 \mathrm{q}$ and $17 \mathrm{p}$ (the latter, p53).

HNPCC has become the model for the third mechanism of tumour genesis (2), ie, altered control of DNA fidelity.

In all cases, individuals at risk for hereditary cancer have a germline mutation that may subsequently be important at a somatic level. In many sporadic tumours the same genetic mutations are seen, although just in somatic tissue. For example, $30 \%$ to $40 \%$ of sporadic colon cancers shown mutations to apc, and $15 \%$ to HNPCC genes.

\section{PREDICTIVE TESTING}

Recommendations for monitoring (1) known or suspected FAP/HNPCC individuals and their families are outlined in Table 1. This is an onerous schedule for both patients and their physicians, as well as an expensive one. Optimally, genetic testing may allow the ruling in or ruling out of individuals at risk for hereditary colon cancer.

Unfortunately, predictive testing for at-risk individuals is far from easy. First, it is not always possible to identify individuals at true increased genetic risk. Because of the frequency of colon cancer in the North American population, many individuals may have one or more relatives with colon cancer of a sporadic nature. Second, one gene does not equal one mutation. Colon cancer can be caused by several genes, and there are multiple known mutations in each. This complicates molecular diagnostics and exponentially increases 
cost. Third, testing procedures often require blood from multiple affected family members. If the family is small or those affected have died, then testing may not be possible. Finally, individuals may not wish to be tested. Negative consequences may accrue to those at risk for a disorder even though it may not manifest for many years. Insurance or emigration may be denied and social or employment discrimination may occur.

As well, the psychological response to knowing that one is likely to develop cancer may be devastating to individuals and families; this may be particularly true for testing of children.

When molecular diagnosis of hereditary colon cancer is successful, the at-risk individual becomes either at very high risk or at very low risk. Those at very low risk may avoid a lot of unpleasant and expensive testing. Those at very high risk (and their physicians) may feel more motivated to follow surveillance protocols. Many patients undergo prophylactic surgery. Unfortunately, reliable preventive treatment for colon cancer does not exist nor are there existing treatment modalities more specific to hereditary (versus sporadic) cancer.

\section{REFERENCES}

1. Rustgi AK. Hereditary gastrointestinal polyposis and nonpolyposis syndromes. N Engl J Med 1994;331:1694-702.

2. Toribara NW, Sleisenger MH. Screening for colorectal cancer. N Engl J Med 1995;332:861-7.

3. Fuchs CS, Giovannucci EL, Colditz GA, et al. A prospective study of family history and the risk of colorectal cancer. N Engl J Med 1994;331:1669-74.

\section{WHAT IS AVAILABLE NOW?}

Linkage and common deletion testing in FAP is available as a service in many molecular diagnostic laboratories throughout Canada. Linkage and replication error repeats for HNPCC are approaching service in some laboratories but are still done mostly on research protocols. Queries regarding assessment of individuals/families at risk for hereditary colon cancer should be made through the medical genetics clinics or specialized hereditary cancer clinics in each province. The Familial Gastrointestinal Cancer Registry at Mount Sinai Hospital in Toronto, Ontario is also an excellent resource for information.

\section{SUMMARY}

Most of our knowledge of hereditary colon cancer has accumulated in this decade, and our understanding of molecular mechanisms in cancer is rapidly improving. Predictive testing for at-risk individuals is available in very limited circumstances; genetic screening on a population basis is not possible. Management in terms of surveillance and prophylactic surgical intervention is also improved but specific treatment, both clinical and genetic, is a goal for the future.

4. Hall NR, Angela M, Williams T, et al. Muir-Torre syndrome: a variant of the cancer family syndrome. J Med Genet 1994;31:627-31.

5. Knudson AG Jr. Genetics of human cancer. Ann Rev Genet 1986;20:231-51.

6. Vogelstein B, Fearon ER, Hamilton SR, et al. Genetic alterations during colorectal-tumor development. N Engl J Med $1988 ; 319: 525-32$ 


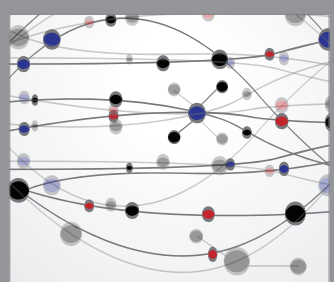

The Scientific World Journal
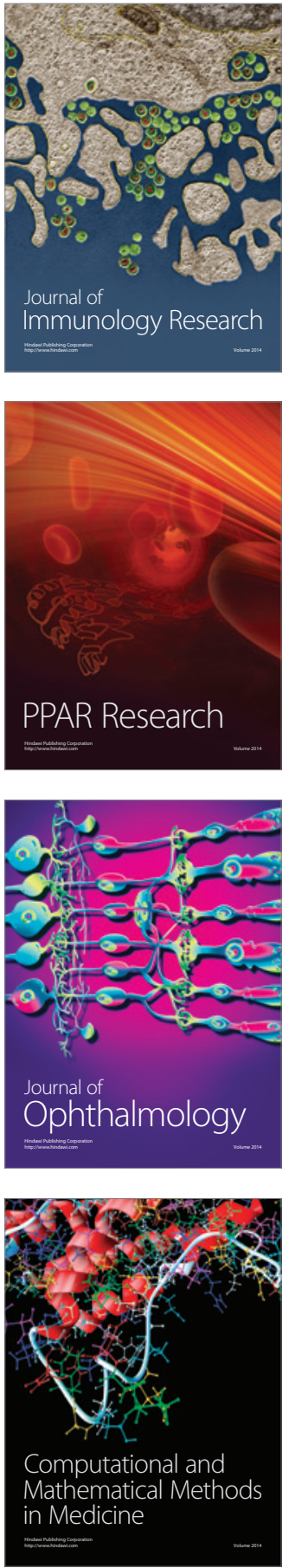

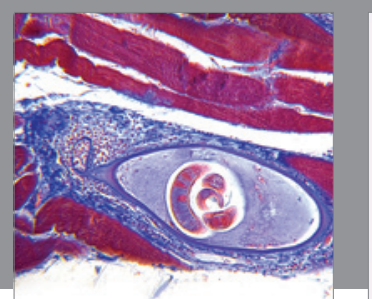

Gastroenterology Research and Practice

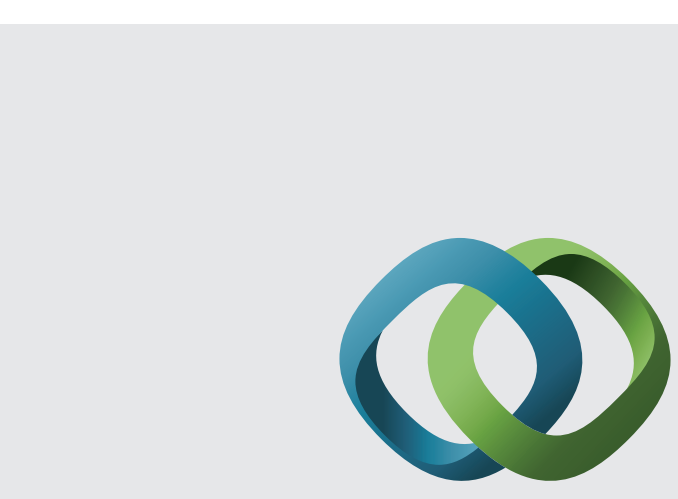

\section{Hindawi}

Submit your manuscripts at

http://www.hindawi.com
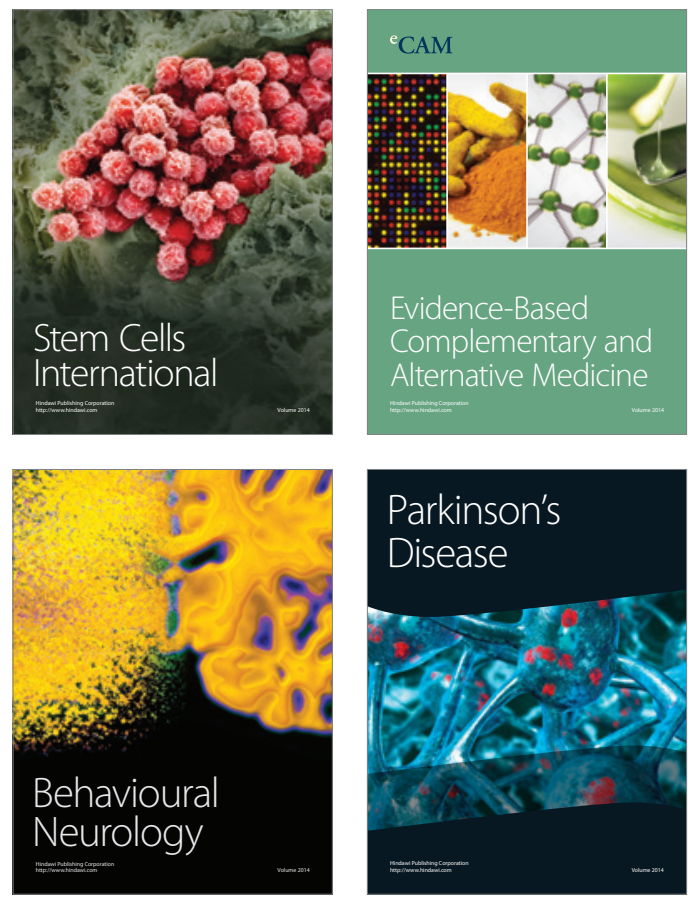
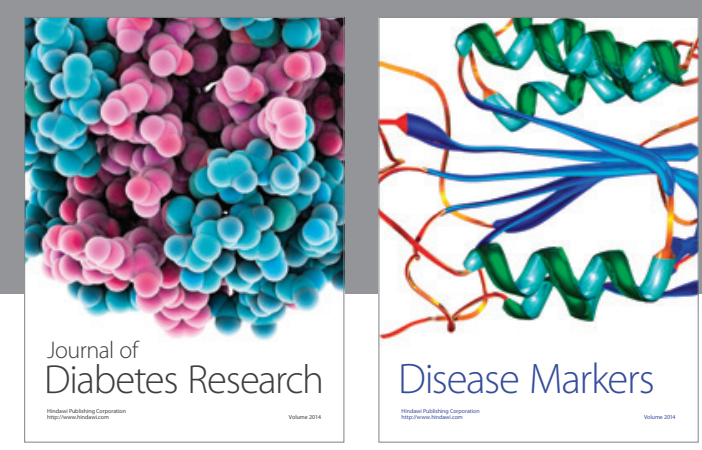

Disease Markers
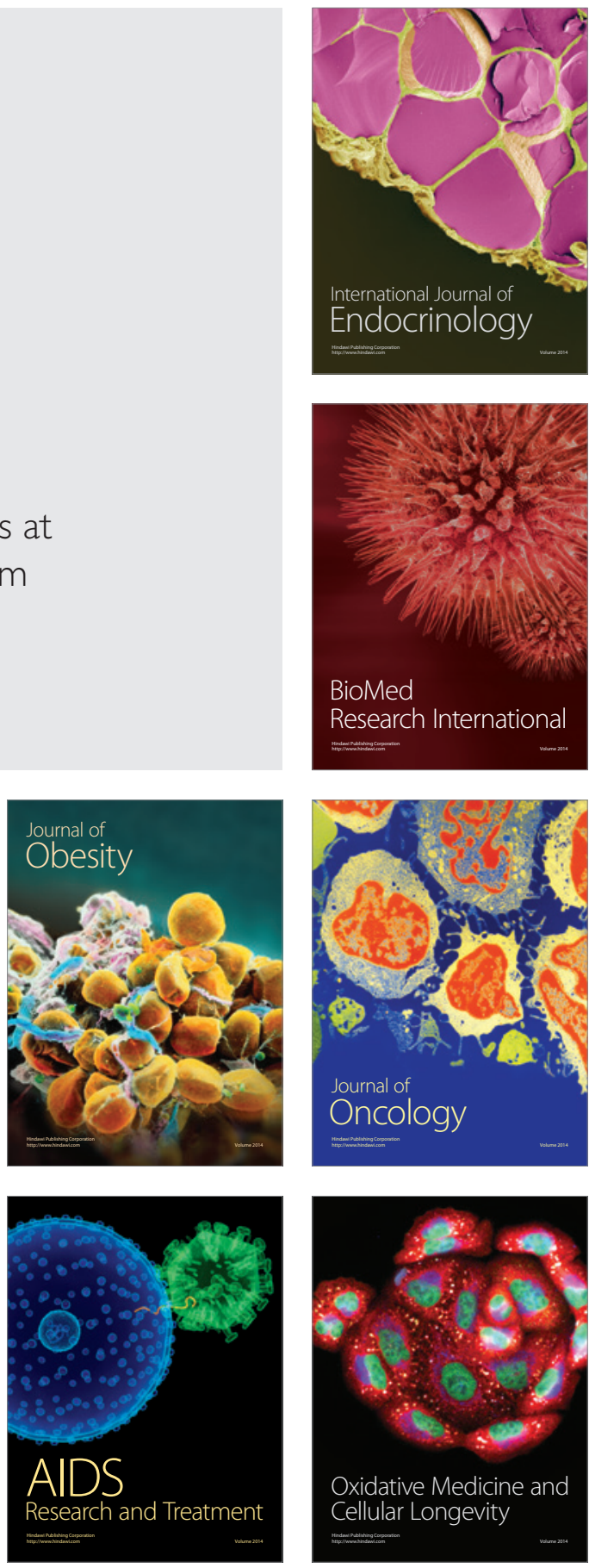